\title{
Tailoring the parametric gain in large mode area hybrid photonic crystal fibers
}

\author{
Petersen, Sidsel Rübner; Lægsgaard, Jesper; Alkeskjold, Thomas Tanggaard
}

Published in:

Frontiers in Optics 2013/Laser Science XXIX

Link to article, DOI:

10.1364/FIO.2013.FM3B.5

Publication date:

2013

Document Version

Publisher's PDF, also known as Version of record

Link back to DTU Orbit

Citation (APA):

Petersen, S. R., Lægsgaard, J., \& Alkeskjold, T. T. (2013). Tailoring the parametric gain in large mode area hybrid photonic crystal fibers. In Frontiers in Optics 2013/Laser Science XXIX [FM3B.5] Optical Society of America. https://doi.org/10.1364/FIO.2013.FM3B.5

\section{General rights}

Copyright and moral rights for the publications made accessible in the public portal are retained by the authors and/or other copyright owners and it is a condition of accessing publications that users recognise and abide by the legal requirements associated with these rights.

- Users may download and print one copy of any publication from the public portal for the purpose of private study or research.

- You may not further distribute the material or use it for any profit-making activity or commercial gain

- You may freely distribute the URL identifying the publication in the public portal 


\title{
Tailoring the parametric gain in large mode area hybrid photonic crystal fibers
}

\author{
Sidsel R. Petersen ${ }^{1, *}$, Jesper Lægsgaard ${ }^{1}$, Thomas T. Alkeskjold ${ }^{2}$ \\ ${ }^{1}$ DTU Fotonik, Technical University of Denmark, Ørsteds Plads Building 343, 2800 Kgs. Lyngby, Denmark \\ ${ }^{2}$ NKT Photonics A/S, Blokken 84, 3460 Birkerød, Denmark \\ *srpe@fotonik.dtu.dk
}

\begin{abstract}
The spectral width of parametric gain peaks due to degenerate four-wave mixing is investigated numerically in large-mode-area hybrid photonic crystal fibers. The width is varied for a maintained pump wavelength and gain maximum position by tailoring the dispersion.

(C) 2013 Optical Society of America
\end{abstract}

OCIS codes: (190.4380) Nonlinear optics, four-wave mixing; (060.5295) Photonic crystal fibers.

\section{Introduction}

Control of the group velocity dispersion (GVD) is the key to control the spectral position of the maximum parametric gain due to a four-wave mixing (FWM) process in silica fibers. For power scaling of the process a large mode area (LMA) is needed, which can make the GVD control troublesome, since the material dispersion dominates in large core fibers. In this work a double-clad hybrid LMA photonic crystal fiber is considered, with an inner cladding consisting of airholes and Germanium-doped silica rods (Ge-rods). An illustration of the fiber is seen in Fig. 1a. The Ge-rods give rise to a photonic bandgap (PBG) effect, and adjustment of the airhole diameters allow for single mode guidance in a LMA core. The diameter of the Ge-rods on one side of the core, $d_{\mathrm{s}}$, is reduced with respect to the diameter on the other side of the core, $d_{1}$, providing control of blue- and red spectral edge of the PBGs [1]. In Fig. 1b the calculated GVD parameter (D) of the fundamental mode (FM) polarized along the Ge-rods is shown for different values of $d_{1}$, while $d_{\mathrm{s}}$ is kept constant at $6 \mu \mathrm{m}$. The ratio $d_{\mathrm{l}} / d_{\mathrm{s}}$ is varied from 1 to 1.2336 in steps of 0.0117 . Near the edges of the PBGs the GVD grows strongly, giving rise to large values of normal and anomalous dispersion, providing control of the GVD independently of core size. In Fig. $1 \mathrm{~b}$ a zoom near the zero dispersion wavelength (ZDW) is also seen. By altering $d_{1}$ it is possible to tune ZDW in a range of $10 \mathrm{~nm}$.

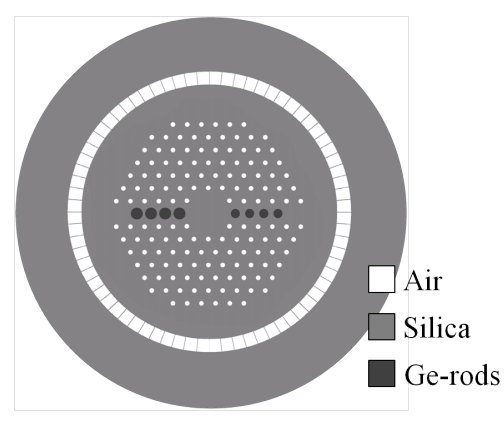

(a)

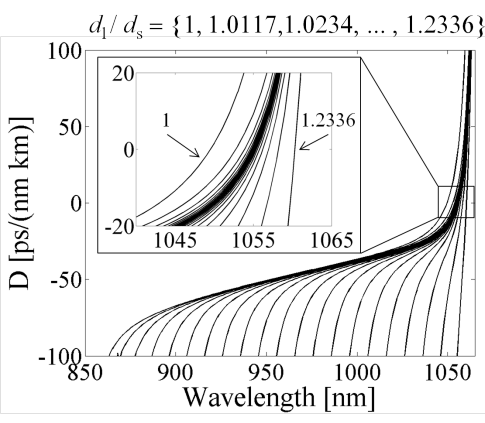

(b)

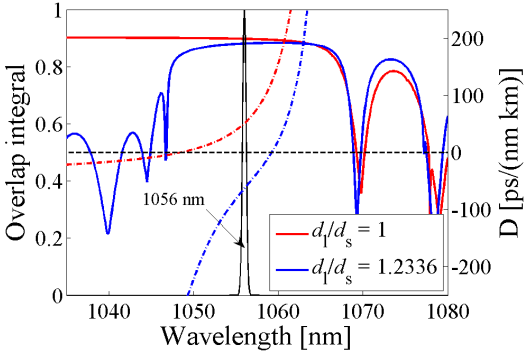

(c)

Fig. 1: (a) Illustration of the double-clad hybrid large-mode-area photonic crystal fiber with an airclad as the outer cladding. (b) Group velocity dispersion in the transmission band for the hybrid photonic crystal fiber for a range of $d_{\mathrm{l}} / d_{\mathrm{s}}=1, \ldots, 1.2336$ in step sizes of 0.0117. A zoom near the zero dispersion wavelength is also shown. (c) Overlap integrals of the fundamental mode polarized along the Germanium-doped silica rods with the core region (solid lines, $\mathrm{y}$-axis on the left) and group velocity dispersion parameters (dashed lines, y-axis on the right) for $d_{1} / d_{\mathrm{s}}=1$ and $d_{\mathrm{l}} / d_{\mathrm{s}}=1.2336$. Furthermore a Gaussian distribution at $1056 \mathrm{~nm}$ illustrates the pump wavelength. 


\section{Tailoring the parametric gain}

Degenerate FWM is a third order nonlinear process. In the process two pump photons are annihilated and one signal and idler photon are created. For the process to take place energy conservation and phase matching must be fulfilled. The parametric gain of the FWM process can be calculated from a set of coupled differential equations [2,3]. Overlap integrals of the interacting pump-, signal-, and idler- fields are included in these equations. The propagation constants and field overlap integrals needed to calculate the parametric gain have been calculated with a full-vector modal solver based on the finite element method.

The spectral position of the maximum parametric gain depends on the dispersion profile. In Fig. 1b it was shown how the spectral position of ZDW can be changed by adjustment of the Ge-rod diameters. However, the slope of the dispersion profile at the bandedges also changes and thus the phasematching condition. In the following a pump wavelength of $1056 \mathrm{~nm}$ will be considered for two different scenarios. The scenarios are illustrated in Fig. 1c, where the two extrema of $d_{1} / d_{\mathrm{s}}$ are considered, 1 and 1.2336, respectively. For the $d_{1} / d_{\mathrm{s}}=1$ the pump is located in the anomalous dispersion regime, $\mathrm{D}=51 \mathrm{ps} /(\mathrm{nm} \cdot \mathrm{km})$, and for $d_{\mathrm{l}} / d_{\mathrm{s}}=1.2336$ the pump is located in the normal dispersion regime, $\mathrm{D}=-65 \mathrm{ps} /(\mathrm{nm} \cdot \mathrm{km})$. In Fig. 2a and Fig. 2b calculated parametric gain curves (solid lines) with $0.1 \mathrm{~nm}$ resolution and pump peak power of $8 \mathrm{~kW}$ are shown for the two scenarios. Furthermore the overlap integral of the fundamental mode polarized along the Ge-rods with the core region is plotted (dashed line) to illustrate the positions of the gain peaks with respect to the transmission bandedges.

From Fig. 2a and Fig. 2b it is clearly demonstrated that the dispersion profile can be tailored to obtain a broader gain peak. Furthermore, the signal wavelength is better confined in the transmission band for $d_{\mathrm{l}} / d_{\mathrm{s}}=1$ than for $d_{1} / d_{\mathrm{s}}=1.2336$. Larger overlap integrals of signal, idler and pump fields are therefore obtained for $d_{1} / d_{\mathrm{s}}=1$, leading to an increase in maximum gain. However, the maximum gain is positioned at $1063.5 \mathrm{~nm}$ and $1068.9 \mathrm{~nm}$ for $d_{1} / d_{\mathrm{s}}=1$ and $d_{\mathrm{l}} / d_{\mathrm{s}}=1.2336$, respectively. The tailoring thus also has an impact on the maximum gain position.

In Fig. $2 \mathrm{c}$ the parametric gain has been calculated for the ratio $d_{\mathrm{l}} / d_{\mathrm{s}}=1$, but now $d_{\mathrm{s}}$ is increased with $0.1 \mu \mathrm{m}$, to shift the red edge of the transmission band and thereby the spectral position of the maximum gain. In this case, the maximum gain is positioned at $1068.9 \mathrm{~nm}$ and GVD for the pump wavelength is given by $\mathrm{D}=8 \mathrm{ps} /(\mathrm{nm} \cdot \mathrm{km})$.

In conclusion, we have shown how the spectral width of the parametric gain peaks can be increased by tailoring of the GVD, for a maintained pump wavelength and spectral position of the maximum gain. The spectral position of the ZDW can be adjusted, by adjustment of the spectral position of the bandedges, controlled through the Ge-rod sizes. A large spectral width of the parametric gain peak will make the parametric gain less sensitive to size fluctuations along the fiber length, which can be detrimental in practice.

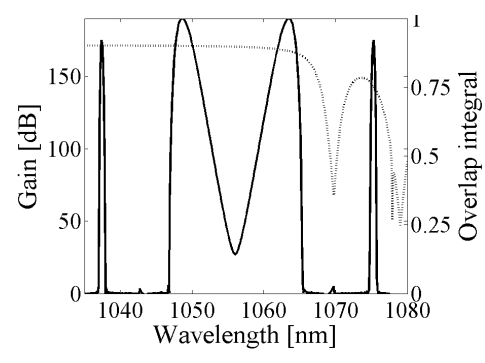

(a)

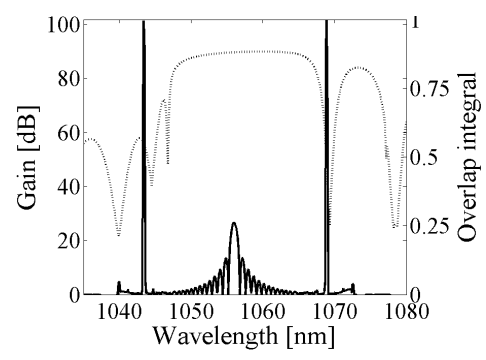

(b)

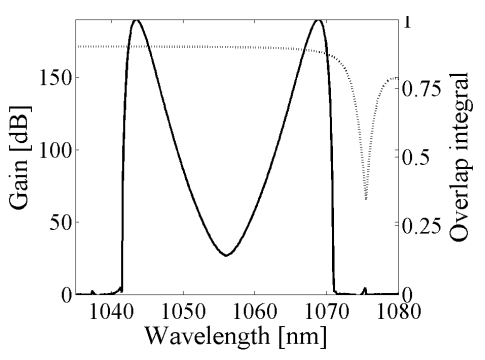

(c)

Fig. 2: Calculated parametric gain (solid line, y-axis on the left) for a pump wavelength of $1056 \mathrm{~nm}$ and overlap integral of the fundamental mode polarized along the Germanium-doped silica rods with the core region (dashed line, $y$-axis on the right). (a) Pump wavelength is positioned in the anomalous dispersion regime, $d_{1} / d_{\mathrm{s}}=1, d_{\mathrm{s}}=6.0 \mu \mathrm{m}$. (b) Pump wavelength is positioned in the normal dispersion regime, $d_{1} / d_{\mathrm{s}}=1.2336, d_{\mathrm{s}}=6.0 \mu \mathrm{m}$. (c) Pump wavelength is positioned in the anomalous dispersion regime, $d_{1} / d_{\mathrm{s}}=1, d_{\mathrm{s}}=6.1 \mu \mathrm{m}$.

\section{References}

1. T. T. Alkeskjold, "Large-mode-area ytterbium-doped fiber amplifier with distributed narrow spectral filtering and reduced bend sensitivity," Opt. Express 17,(19) 16394-16405 (2009).

2. J. Hansryd and P. A. Andrekson, "Fiber-Based Optical Parametric Amplifiers and Their Applications," IEEE J. Sel. Topics Quantum Electron. 8,(3) 506-520 (2002).

3. Govind P. Agrawal, "Nonlinear Fiber Optics," Elsevier, United States of America, Fourth edition, 2007. 